\title{
THE ANALYSIS OF M|M(A,B)|1 ON UNOBSERVABLE AND PARTIALLY OBSERVABLE WAITING LINE WITH REPEATED VACATIONS
}

\author{
D. ANANDAKUMAR, S. PALANIAMMAL and N. NAGAVENI \\ Scholar, Assistant Professor, Department of Mathematics, Sri Krishna College of Engineering and \\ Technology, Coimbatore 641008. \\ Mail id: anandakumardurai30@gmail.com \\ Supervisor, Professor, Principal, Sri Krishna Adithya College of Arts and Science, Coimbatore 641042. \\ Joint Supervisor, Professor and Head, Department of Mathematics, Coimbatore Institute of Technology, \\ Coimbatore 641014.
}

\begin{abstract}
The General Bulk Service Rule (GBSR) is implemented on $M\left|M^{(a, b)}\right| 1$ for the ardent customers. The model is designed for the system with single server and repeated vacations. The high priority batch is contributed with better service and the First Come First Served (FCFS) queuing manner is applied to the batches. The server begins to serve when 'a' customers are available in the queue and after completing the service if the server identifies at most ' $b$ ' customers in the queue then server takes all the customers and put them in a batch and when the server discovers more than $b$ customers in the waiting line, the server will provide the service for the first ' $b$ ' customers in a batch and rest of the customers are put in the waiting line. The customers get in the queue in the poison fashion and service time of every batch area is presumed to be distributed exponentially with respect to mean dependent batch area and customers may eschew or break if the waiting line of the customers are tend to be very large. In this method, server can take vacation when less than ' $a$ ' customers are present in the queue. The diverse performance metrics on effectiveness are examined and the model is inspected based on eschewing and breaking probability.
\end{abstract}

Keywords: General bulk service, First Come First Serve, eschew and break, repeated vacation, poison process, and performance metrics

\section{INTRODUCTION}

The demanding queuing theory models are developed for the applications such as computer technology, traffic control, military area and other areas for constructing a scheme for effectual model and examining the various metrics including waiting line of the customers and server vacation time. The server vacation queuing model has a broadscale of applicability in general engineering areas. Queueing systems accompanied by server vacations have been substantially practiced in various areas including manufacturing systems, communication systems, production inventory systems and call centers. This type of queuing criteria appears in real time systems that includes communication network, manufacturing, etc. Accordingly, the strategies for vacations are stated based on the scheduling methods. If there is no customer present in the system, the vacation period starts. The assumptions about the queuing system predict the underlying state of the system and to find the suitable means to minimize the waiting line or queue. Whenever the customer

Received JUN 22, 2021 www.dynamicpublishers.com; www.dynamicpublishers.org;
ISSN1056-2176(Print); ISSN 2693-5295 (online) $\$ 15.00$ CDynamic Publishers, Inc. https://doi.org/10.46719/dsa202130.09.07 
appears, the service starts right away in many queuing theories. Still there are some systems where the servers move out of the system for the continual task called vacation. Many queuing models are developed and examined for single server vacation by number of authors. Owing to the wide applications in computer technology and other systems, many queuing theories has been analyzed.

The semi vacation concept was found by Servi and Finn (9) where the server entirely quits the service throughout the vacation period and the service is provided at the lower rate. Most of the servers operates the system at the lower rate or quits the service or alternate server may offer the service during the period of vacation. When the service rate dissipates to the value of zero, this model becomes classical vacation. The queuing theory based on $E_{k}\left|M^{(a, b)}\right| 1$ and the solutions were developed by M.I.Afthabbegam (1) in which the system contains single server and many vacations. The survey on $\mathrm{M}|\mathrm{G}| 1 \mid \mathrm{N}$ queuing model accompanied by server vacation and complete service is examined by Doshi and Takagi.H (2). The concept of general bulk service with more than one server is established by Medhi.J and Borthakur (5). Tian and Zhang (10) modeled a partial server vacation model with multiple queues where the service gets completely stopped during the server vacation. The working vacation model differs from classical model because the former customers may complete the service and leave the system whereas in classical model the server will definitely leave the system.

The study on $\mathrm{M}|\mathrm{M}| 1$ queuing model was performed by Servi and Finn (9) with repeated operating vacation periods and acquired the customers present in the queue, waiting queue line distribution and analysis on performance metrics including queue length and service time. The work on multiple vacation model denoted by $\mathrm{M}|\mathrm{G}| 1$ was generalized by $\mathrm{Wu}$ and Takagi [11]. In queuing theory, a rule that present in the mathematical theory of probability, an M/G/1 queue is a queuing model in which occurrences are Markovian that are modulated using Poisson method, service times possess a General distribution and a single server is present. The compulsory vacation model was enhanced by Madan. The single vacation policy represented by $M|M| 1$ and it is developed for the minimum systems with minimum customers when the operational capability of the system is low to reduce the computational cost issues and consumption of energy. The model was based on quasi birth and death sequence of the system to identify the likelihood of the customers in the system and the time taken to service the high priority queue by Naishuo Tian and Xinqiu Zhao (7). 
The fuzzy sets logic was developed by Zadeh (12) and the fuzzy queuing models are examined. In fuzzy environment, Kao et al (3) introduced a parametric programming queuing system which is the extension principle of Zadeh. The bulk arrival fuzzy queues have been determined by Nagoor Kani. A and V. Ashok Kumar (6) and obtained the fuzzy outputs. The Robust Ranking technique evaluates the performance measures of bulk arrival queue by Palpandi.B and Geedhamani.G (8). The Robust Ranking technique is applied to acquire the system performance for the bulk arrival queues.

In this method, the analysis is made on $\mathrm{M}\left|\mathrm{M}^{(\mathrm{a}, \mathrm{b})}\right| 1$ using unobservable and partially observable waiting line for repeated vacation procedure with minimum eschewing and breaking rate. The service time of the batch varies from "a" to "b" and it is entirely dependent upon the amount of customers present in the queue. The server will take vacation until "a" minimum amount of customers reach the system. When a server sees at least minimum amount of customers in the system (i.e. "a"), then the server returns from the vacation. The arrival pattern of customers occurs in poison manner and the maximum limit is "b" and if the size exceeds more than $b$, then initial "b" batch customers are attended first and other customers will be in the next waiting line. If the arriving customers identifies more than "b" customers, he may decide to eschew. The customers already present in the waiting line may decide to break depending on the service time.

The rest of the paper is constructed as follows: section 2 furnishes the brief model explanation of the system, section 3 describes the mathematical formulation and assumptions of the system, the performance measures of the system are given in section 4 and section 5 illustrates the numerical computations of the system.

\section{MODEL DESCRIPTION}

The customers are processed in batches by the server based on general bulk service rule (GBSR). In Bulk service queueing models, customers are served in batches, the batches may be of fixed length or variable length. Sometimes, the service rate may be contingent on the amount of customers holding back to avail service. In this method, the server begins the service only when he sees the minimum of "a" customers inside the system. When the server completes the service and then the batch processing takes place when he identifies "b" number of maximum customers in the system. When more than "b" customers reach the system, then initial "b" customers are 
placed in the batch and service is provided for first "b" customers and rest of the customers are placed in the queue and it is depicted in figure 1. Each service batch is comprised of "a" customers and highest number of "b" customers. The service time of batch size is distributed independently with the parameter $\psi$.

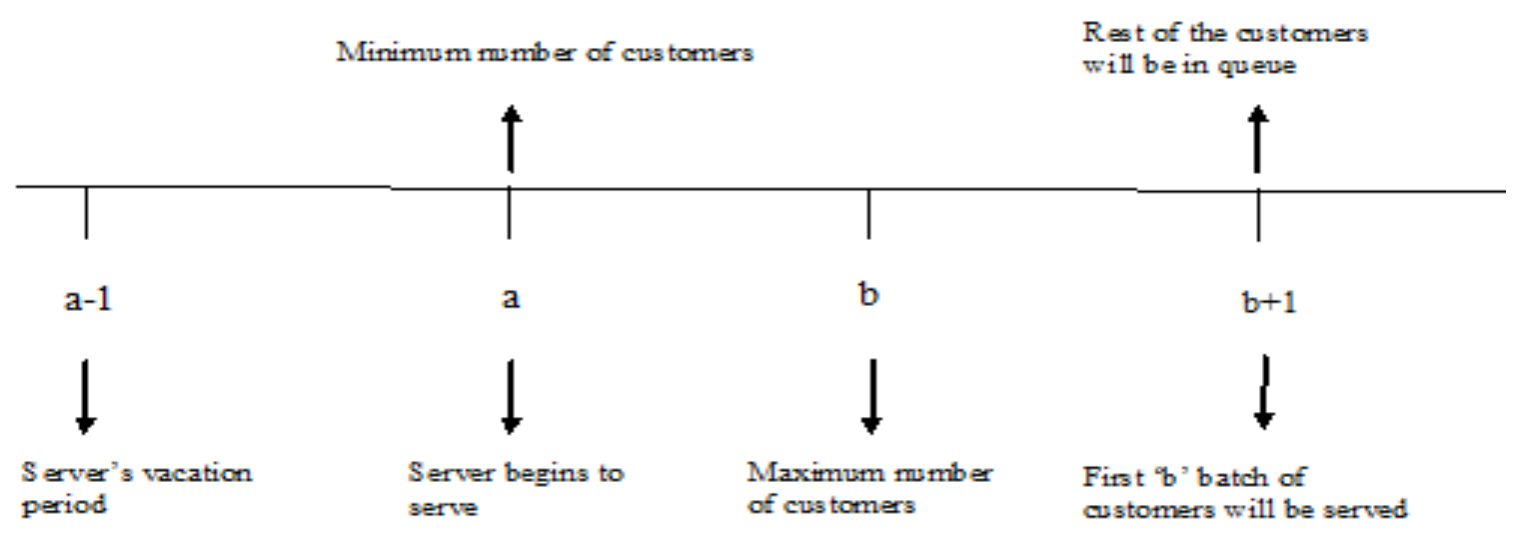

Figure No.1 Model Description of Queuing System

From figure No.1, explained the complete concept of customer and rate of service. The server may take vacation when there are less than "a" customers in the system. The server will provide service to the customers until the customer level is minimum number of "a" or maximum of " $b$ " customers in the system. The server continues the service till the customer level becomes less than "a". The rest of the customers those who hold back may choose to eschew or break. The customers arrive in batches rather than one at a time. There are two cases to consider: The first thing is, when the waiting line is very large, and then customer may not enter the system and decide to eschew. Eschewing is customers do not enter the system after seeing the long queue. The second thing is when the customer decides to enter the waiting line and after sometime he may decide to leave the queue after losing his patience and this case is said to be breakd.

The following assumptions are used to govern the queuing system:

- The customers reach the system in the order by poison distribution and the rate of arrival is denoted by $\eta$.

- The queuing discipline is First Come First Serve (FCFS). 
- The mean service rate is $\psi$.

- $\eta$ and $\psi$ should be equivalent to 1/Ex [time of inter-arrival] where Exrepresents the operator of expectation.

- The server utilization, probability of busy server or customer being served is given by $\epsilon=$ $\eta / \psi$.

- The total amount of servers is c.

- $P_{n}$ denotes the probability of $n$ amount of customers in the system.

- $L$ value is calculated to identify the mean amount of customers in the system $\rightarrow \mathrm{L}=\eta$.W.

- $\mathrm{L}_{\mathrm{q}}$ calculates the mean value of number of customers present in the queue $\rightarrow \mathrm{L}_{\mathrm{q}}=\eta \cdot \mathrm{W}_{\mathrm{q}}$.

- The queue's mean wait is $\mathrm{W}_{\mathrm{q}}$.

- The system's mean wait is $\mathrm{W} \rightarrow \mathrm{W}=\mathrm{W}_{\mathrm{q}}+1 / \psi$.

- Compute $\mathrm{C}^{2}=$ variance/ $(\text { mean })^{2} \rightarrow \mathrm{C}^{2}$ is the random variables coefficient variation.

- The squared coefficient of variation of service time is represented by $\mathrm{C}_{\mathrm{s}}^{2}$.

- The squared coefficient of variation of time of inter-arrival is represented by $\mathrm{C}^{2}$ a.

- The service time variation is $\sigma_{\mathrm{s}}^{2}$.

- The total capacity of the waiting line (queue) is $\mathrm{k}$ : $\mathrm{k}=\infty$.

- For the queuing model $\mathrm{M}\left|\mathrm{M}^{(\mathrm{a}, \mathrm{b})}\right|$, the mean value of number of customers can be computed by proving $\mathrm{L}_{\mathrm{q}}=\epsilon^{2} /(1-\epsilon)$. Still the accurate output can be obtained by approximation calculation method and it is denoted by,

$\mathrm{L}_{\mathrm{q}} \approx \epsilon^{2}\left(1+\mathrm{C}_{\mathrm{s}}^{2}\right)\left(\mathrm{C}_{\mathrm{a}}^{2}+\epsilon^{2} \mathrm{C}_{\mathrm{s}}^{2}\right) / 2(1-\epsilon)\left(1+\epsilon^{2} \mathrm{C}_{\mathrm{s}}{ }_{\mathrm{s}}\right)$

- If the arrival rate of customers is $\eta$ and inter arrival time variance is $\sigma^{2}$ a then compute:

$$
C^{2}{ }_{a}=\sigma_{a}^{2} /(1 / \eta)^{2}
$$

- If rate of service time is $\psi$ and service time variance is $\sigma^{2}$ s then calculate:

$$
\mathrm{D}^{2}{ }_{\mathrm{s}}=\sigma_{\mathrm{s}}{ }_{\mathrm{s}} /(1 / \psi)^{2}
$$

The parameters $(\mathrm{a}, \mathrm{b})$ are uniformly distributed by the random variable $\mathrm{Z}$ where a represents the minimum amount of customers and $\mathrm{b}$ represents the maximum number of customers. The expected mean value of customer $\mathrm{Z}$ is $(\mathrm{a}+\mathrm{b}) / 2$, its variance $=(\mathrm{b}-\mathrm{a})^{2} / 12$. The mean arrival rate is $1 / \eta$ and the variance is $1 / \eta^{2}$ for its exponential distribution. The mean, variance of the inter arrival time is represented by $\mathrm{E}(\mathrm{Z})$ and $\mathrm{V}(\mathrm{Z})$. 
Consider the scenario to calculate the amount of customers present in the system and the mean wait queue. The model is $M\left|M^{(a, b)}\right| 1$ single server system and when $\eta=1 / 10$; the variance of the time of inter-arrival is 2 .

The mean value of the service time can be given as $(9+7) / 2=8$, i.e., $\psi=1 / 8$.

Similarly, the variance value of the service time, $\underset{S}{\sigma} 2$ is equivalent to $(7-9) 2 / 12=1 / 3$. Also, $\epsilon=$ $8 / 10$.

Then:

$\underset{a}{\mathrm{D}} 2=\underset{s}{\sigma} 2(1 / \eta)^{2}=0.02$

$\underset{s}{\mathrm{D}} 2=\underset{s}{\sigma} 2\left(\underline{(1 / \psi)^{2}=1 / 192}\right.$

Queue count can be given as

$$
\mathrm{Lq}=\epsilon^{2}(1+\underset{s}{\mathrm{D}} 2)\left(\underset{a}{\mathrm{D}} 2+\epsilon^{2} \underset{s}{\mathrm{D}} 2\right)
$$

$2(1-\epsilon)\left(1+\epsilon^{2} \underset{s}{\mathrm{D}} 2\right)$

$=0.037$

Time of wait in the Queue $=\mathrm{Wq}=\mathrm{Lq} / \eta=0.373$ minutes.

Time of wait in the system $=\mathrm{Wt}=\mathrm{Wq}+1 / \psi=8.373$ mins.

Number present in the system $=\mathrm{L}=\eta \mathrm{Wt}=0.8373$.

Percentage of idle time by the server $=1-\epsilon=0.2$.

\section{MATHEMATICAL FORMULATION AND ASSUMPTIONS}

A single server is present in the system to furnish service to the customers present in the queue. He will be in service or he can avail vacation based on the amount of customers in the system. The server can only be present in the system when there is a, $a+1 \ldots, b, b+1$ customers in the overall system. When a-1 customers present in the system then server can take vacation. There are two cases: when a customer finds a long queue, he may choose not to get in the system which 
is said to eschew and when a customer enters the queue and after losing his patience he may decide to leave the queue which is said to break.

The service time is independent according to the two finite sets $\mathrm{B}[\mathrm{X}], \mathrm{E}[\mathrm{B}]<\infty$ and $\mathrm{E}\left[\mathrm{B}^{2}\right]<\infty$. The server time is indicated by $\mathrm{R}_{\mathrm{B}}$. When the system contains less than "a" customers then server starts his vacation period. When server identifies the empty queue at the end of his vacation, again server can avail vacation till the system reaches its level. This method is called repeated vacation. When the waiting line turns to be positive, then server begins his service. Like service time, the vacation times are also independent and observe the probability distribution function denoted by $\mathrm{V}[\mathrm{X}]$ with the finite sets $\mathrm{E}[\mathrm{V}]<\infty$ and $\mathrm{E}\left[\mathrm{V}^{2}\right]<\infty$ and the vacation time is indicated by $\mathrm{R}_{\mathrm{v}}$.

The upcoming model is based on the customers by deciding to eschew or break. Here the customers benefit is determined by considering the bonus for service acceptance minus the cost of waiting. The bonus of " $\mathrm{K}$ " units are obtained by the customer for the service completed. The waiting cost of the customer is indicated by $\mathrm{W}_{\mathrm{c}}$ i.e. amount of customers staying in queue to avail service. Suppose the condition is taken,

$\mathrm{K}>\mathrm{C}\left(\mathrm{E}\left[\mathrm{R}_{\mathrm{v}]}+\mathrm{E}[\mathrm{B}]\right)\right.$

Which denotes that the server is in vacation where the service bonus is greater than cost of waiting. This indicates that the customer needs to wait till the vacation period gets completed. To justify (1), the customer must know the vacation time $E\left[R_{v}\right]$ and service time $E[B]$ in order to enter into the system. If this equation (1) does not exist, then the customer decides not to enter into the empty system after the first exit. There are two cases to consider: one is unobservable waiting line and the second one is partially observable waiting line.

- Unobservable Waiting Line - the system state is not observed by the customer when he decides to join the queue and after some time impatient customers may break or eschew.

- Partially Waiting Line - the current position of the server is noticed by the customer but failed to notice the queue size and then decides to enter the queue and impatient customers may break or eschew.

The decisions taken by the customer in both cases are unchangeable and also the new trial cannot be initiated for eschewed and breakd customers. 


\subsection{The Unobservable Waiting Line}

In this queue, the customers who enter the system needs to undergo two procedures. i) eschewing - the value is 0 ii) join or breaking - the value is 1 . Combining these two procedures, customer arrives with the probability $q \in(0,1)$

\section{i) The Expected Sojourn Time}

The customers arrive in the poison fashion and follow the procedure q, and the rate of arrival is $\eta_{\mathrm{q}}$. The outcome of this approach is $\mathbf{M}\left|\mathbf{M}^{(\mathrm{a}, \mathrm{b})}\right| 1$ with recurrent vacations and the arrival rate is $\eta_{\mathrm{q}}$. Here the service time and vacation times are described. The upcoming lemma is taken from Fuhrmann's decomposition theorem.

Lemma 1 The equation $\eta_{\mathrm{q}} \mathrm{E}[\mathrm{B}]<1$

(2) holds

when the customer arrival follows the common procedure $q$ (since $q \epsilon(0,1)$ ) in an unobservable waiting line. The mean visit time of the customer who enter the line is given by,

$\mathrm{E}[\mathrm{S}]=\mathrm{E}\left[\mathrm{R}_{\mathrm{v}}\right]+\mathrm{E}[\mathrm{B}]+\eta_{\mathrm{q}} \mathrm{E}[\mathrm{B}] / 1-\eta_{\mathrm{q}} \mathrm{E}[\mathrm{B}] . \mathrm{E}\left[\mathrm{R}_{\mathrm{B}}\right]$

\section{ii) The Stable Eschewing Strategies}

The customer responses are evaluated in stable equilibrium. The first step is : the system must be stable. But, when the system is in unstable state then mean visit time of each customers in the system will be infinite. Hence the eschewing or breaking methods will be the perfect method for the unstable system. Still the stable system strategies have to be limited in the in the interval $[(0,1) /(\eta \mathrm{E}[\mathrm{B}])) \cap[0,1]$.

Once looking the unobservable staying queue, the arriving customers may choose to eschew, and it is equal to 0 . But, when he decides to join the system or after joining when he decides to break after losing his patience then the expected utility can be indicated by,

$$
\begin{aligned}
& \mathrm{U}_{\mathrm{e}}(\mathrm{q})=\mathrm{K}-\mathrm{CE}[\mathrm{S}] \\
& =\mathrm{K}-\mathrm{C}\left(\mathrm{E}\left[\mathrm{R}_{\mathrm{v}}\right]+\mathrm{E}[\mathrm{B}]+1-\eta_{\mathrm{q}} \mathrm{E}[\mathrm{B}] / 1-\eta_{\mathrm{q}} \mathrm{E}[\mathrm{B}] . \mathrm{E}\left[\mathrm{R}_{\mathrm{B}}\right]\right)
\end{aligned}
$$

The above equation holds for any probability $\mathrm{q} \epsilon[(0,1) /(\eta \mathrm{E}[\mathrm{B}]))$, the customers who are tagged in the system will be in the system itself till service completion when $U_{e}(q)>0$ and he is uninvolved among breaking and eschewing customers if $\mathrm{U}_{\mathrm{e}}(\mathrm{q})=0$ and customers may decide to 
eschew if $U_{e}(q)<0$. The customers who are in the waiting line may decide to break when the probability $\mathrm{q} \geq 1 /(\eta \mathrm{E}[\mathrm{B}])$.

The $\mathrm{U}_{\mathrm{e}}(\mathrm{q})$ in equation (4), the value of $\mathrm{q}$ is decreasing, and it owns a distinct root $\mathrm{q}_{\mathrm{e}}{ }^{*}$. The distinct root is expressed by,

$$
\mathrm{q}_{\mathrm{e}}{ }^{*}=1 /(\eta \mathrm{E}[\mathrm{B}]) \cdot\left(1-\left(\mathrm{E}\left[\mathrm{R}_{\mathrm{B}}\right] /(\mathrm{K} / \mathrm{C})-\mathrm{E}\left[\mathrm{R}_{\mathrm{v}}\right]-\mathrm{E}[\mathrm{B}]+\mathrm{E}\left[\mathrm{R}_{\mathrm{B}}\right]\right)\right.
$$

The decreasing nature of $U_{e}(q)$ will be allowed to observe the condition $U_{e}(q)>0$ for all $\mathrm{q}<\mathrm{qe}^{*}$.

i) $\quad \mathrm{U}_{\mathrm{e}}\left(\mathrm{q}_{\mathrm{e}}^{*}\right)>0$ for all $\mathrm{q}<\mathrm{q}_{\mathrm{e}}{ }^{*}$

ii) $\quad \mathrm{U}_{\mathrm{e}}\left(\mathrm{q}_{\mathrm{e}}{ }^{*}\right)=0$ and $\mathrm{U}_{\mathrm{e}}(\mathrm{q})<0$ for all $\mathrm{q}>\mathrm{q}_{\mathrm{e}}{ }^{*}$

The next state is, when $\mathrm{q}_{\mathrm{e}}{ }^{*}<1$ the response strategy which gives the best is $\mathrm{qe}_{\mathrm{e}}{ }^{*}$ and joining probability strategy will be $\mathrm{q}_{\mathrm{e}}{ }^{*}$. When $\mathrm{q}_{\mathrm{e}}{ }^{*} \geq 1$ and $\mathrm{U}_{\mathrm{e}}(\mathrm{q}) \geq 0$ for all $\mathrm{q} \in[0,1]$ and the method of joining probability in equation (1) is not applicable in unique method.

\subsection{The Partially Observable Waiting Line}

The present server's status is observed in this section. Based on the server information the customers who arrive to the system choose whether to eschew or enter the system and break. But the occupancy of the system cannot be noticed by the arriving customers. The four strategies exist here for eschewing and breaking customers.

i) Always eschew and break $(0,0)$

ii) If the server stays in vacation, the customers may eschew or break when the state is $(0,1)$

iii) If the server starts his duty, then the customer may eschew or break in the condition $(1,0)$

iv) The customer never eschews or break when the state is $(1,1)$

This procedure is mixed combination i.e. $\left(\mathrm{q}_{0}, \mathrm{q}_{1}\right)$. Here $\mathrm{q}_{\mathrm{i}}$ indicates the joining (breaking) or eschewing probability when the current state "i" of the server $\mathrm{i} \epsilon\{0,1\}$. The conditional expected visit time is calculated by applying the mean value analysis with respect to the strategy $\left(\mathrm{q}_{0}, \mathrm{q}_{1}\right)$. The inequality condition $\eta \mathrm{q}_{1} \mathrm{E}[\mathrm{B}]<1$ is considered. Here,

- $\mathrm{L} \rightarrow$ amount of customers present in the system

- $\quad \mathrm{I} \rightarrow$ server status ( 1 for on and 0 for off)

- $\mathrm{S} \rightarrow$ customers sojourn time 
- $\mathrm{P}_{\mathrm{i}} \rightarrow$ steady state probability where server is in state " $\mathrm{i}$ " hence $\mathrm{i} \in\{0,1\}$

Hence $L_{i}$ is the amount of customers present in the system with the given state " $i$ " and $S_{i}$ will be the customers staying time at the server state "i" and enters the system where $i \in\{0,1\}$. The effective arrival rate $\bar{\lambda}=\eta\left(\mathrm{q}_{0} \epsilon_{0}+\mathrm{q}_{1} \epsilon_{1}\right)$

The equalities are derived by using little's law,

$\epsilon 1=\bar{\lambda} E[B]$

$\mathrm{E}[\mathrm{L}]=\bar{\lambda} \mathrm{E}[\mathrm{S}]$

Where $\mathrm{E}[\mathrm{L}]$ is $\mathrm{E}[\mathrm{L}]=\epsilon_{0} \mathrm{E}\left[\mathrm{L}_{0}\right]+\epsilon 1 \mathrm{E}\left[\mathrm{L}_{1}\right]$. The equation (5) and (6) can be subjected to $\mathrm{p}_{0}$ $+\mathrm{p}_{1}=1$ and

$\epsilon_{0}=\left(1-\eta q_{1} E[B]\right) /\left(1-\eta\left(q_{1}-q_{0}\right) E[B]\right)$

$\epsilon_{1}=\left(\eta q_{0} E[B]\right) /\left(1-\eta\left(q_{1}-q_{0}\right) E[B]\right)$

$\bar{\lambda}=\left(\eta q_{0}\right) /\left(1-\eta\left(q_{1}-q_{0}\right) E[B]\right)$

The equations from (5) to (10) is used to generate $\mathrm{E}[\mathrm{S}]$ such that,

$\mathrm{E}[\mathrm{S}]=\left(1-\eta \mathrm{q}_{1} \mathrm{E}[\mathrm{B}]\right) \mathrm{E}\left[\mathrm{S}_{0}\right]+\eta \mathrm{q}_{1} \mathrm{E}[\mathrm{B}] \mathrm{E}\left[\mathrm{S}_{1}\right]$

This equation (11) can be denoted as the expectation value of the customers staying time. The customer present in the system finds that the server is on vacation and it is distributed identically to $\mathrm{L}_{0}$ amount of customers at the arbitrary amount of time. If the server is on vacation period, customer starts entering the system and joins the system based on poison process rate $\rceil q_{0}$. The equation is obtained by,

$\mathrm{E}\left[\mathrm{S}_{0}\right]=\mathrm{E}\left[\mathrm{R}_{\mathrm{v}}\right]+\left(\mathrm{E}\left[\mathrm{L}_{0}\right]+1\right) \mathrm{E}[\mathrm{B}]$

The customers who are near the system and when he finds server is doing his duty then they will be in the system for rest of their service time $R_{B}$ by which the customer is served and the succeeding service time $\mathrm{L}_{0}$. Thus, the following equation is obtained:

$\mathrm{E}\left[\mathrm{S}_{1}\right]=\mathrm{E}\left[\mathrm{R}_{\mathrm{B}}\right]+\mathrm{E}\left[\mathrm{L}_{1}\right] \mathrm{E}[\mathrm{B}]$ 
When the waiting line equals to the arriving customers with the poison rate $\eta q_{0}$ during the server's vacation period then the vacation time and customers arriving time are distributed identically. Then the equation is obtained:

$\mathrm{E}\left[\mathrm{L}_{0}\right]=\eta \mathrm{q}_{0} \mathrm{E}\left[\mathrm{R}_{\mathrm{v}}\right]$

The subsequent lemma is obtained from the equations (7) and (11) to (14), the equations (14) and (15) are obtained from (13).

Lemma 2The partially observable waiting line is taken, where the common procedure $\left(\mathrm{q}_{0}, \mathrm{q}_{1}\right)$ is followed by the arriving customers in a stable system and the equation $\eta \mathrm{q}_{1} \mathrm{E}[\mathrm{B}]<1$ holds. The customers who join the system and their mean conditional sojourn time is calculated by,

$\mathrm{E}\left[\mathrm{S}_{0}\right]=\mathrm{E}\left[\mathrm{R}_{\mathrm{v}}\right]+\left(\eta \mathrm{q}_{0} \mathrm{E}\left[\mathrm{R}_{\mathrm{v}}\right]+1\right) \mathrm{E}[\mathrm{B}]$

$E\left[S_{1}\right]=\left(\eta q_{0} E\left[R_{v}\right]+1\right) E[B]+E\left[R_{B}\right] /$

$\left(1-\eta q_{1} \mathrm{E}[\mathrm{B}]\right)$

The expected level of queue is obtained by,

$E[L]=\underline{\eta q_{0}\left(E\left[R_{v}\right]+\left(\left(\eta q_{1} E\left[R_{B}\right]\right)\right.\right.}$

$\left.\left(1-\eta q_{1} E[B]\right)+1\right) \cdot E[B] /\left(1-\eta\left(q_{1}-q_{0}\right) E[B]\right)$

i) Balanced Eschewing and Breaking Strategies

The customer follows a common procedure $\left(\mathrm{q}_{0}, \mathrm{q}_{1}\right)$ and the customer arrivals are marked in order to obtain the balanced eschewing and breaking strategy. When the customer in the system after losing his patience and when he decides to break then his net benefit becomes 0 without considering the current status of the server. The expected utility is calculated by considering the customer arrival during server vacation is denoted by $\mathrm{U}_{\mathrm{e}}\left(0 ; \mathrm{q}_{0}\right)=\mathrm{K}-\mathrm{CE}\left[\mathrm{S}_{0}\right]$ but this statement does not depend on $\mathrm{q}_{1}$. The equation (15) gives

$\mathrm{U}_{\mathrm{e}}\left(0 ; \mathrm{q}_{0}\right)=\mathrm{K}-\mathrm{C}\left(\mathrm{E}\left[\mathrm{R}_{\mathrm{v}}\right]+\left(\eta \mathrm{q}_{0} \mathrm{E}\left[\mathrm{R}_{\mathrm{v}}\right]+1\right) \mathrm{E}[\mathrm{B}]\right.$

(18) When server doesn't take repeated vacation the eschewing and breaking rate may decrease. Hence the customers in the system will not leave or break the system during service time of the server and the expected utility is $\mathrm{U}_{\mathrm{e}}\left(1 ; \mathrm{q}_{0} \mathrm{q}_{1}\right)=\mathrm{K}-\mathrm{CE}\left[\mathrm{S}_{1}\right] . \mathrm{E}\left[\mathrm{S}_{1}\right]$ is taken from the equation (16). The notation 
$\mathrm{U}_{\mathrm{e}}\left(1 ; \mathrm{q}_{\circ} \mathrm{q}_{1}\right)=\mathrm{K}-\mathrm{C}\left(\eta \mathrm{q}_{0} \mathrm{E}\left[\mathrm{R}_{\mathrm{v}}\right]+1\right) \mathrm{E}[\mathrm{B}]+\mathrm{E}\left[\mathrm{R}_{\mathrm{B}}\right] /\left(1-\eta \mathrm{q}_{1} \mathrm{E}[\mathrm{B}]\right)$

where

$\mathrm{q}_{1} \in\left(0,1 /(\eta \mathrm{E}[\mathrm{B}])\right.$ else $\mathrm{U}_{\mathrm{e}}\left(1 ; \mathrm{q}_{0} \mathrm{q}_{1}\right)=-\infty$.

For the balanced strategy $\left(\mathrm{q}_{0}, \mathrm{q}_{1}\right)$, the value of $\mathrm{q}_{0}$ is obtained without considering $\mathrm{q}_{1}$. The value of $\mathrm{q}_{0}$ is obtained by the equation (18) and $\mathrm{q}_{1}$ by (19). The value $\mathrm{U}_{\mathrm{e}}\left(0 ; \mathrm{q}_{0}\right)$ is independent of $\mathrm{q}_{1}$ when server is present in vacation period and customers in the waiting line join the system by viewing the customers present in the system and join the system and join the system during current status of server's vacation period.

\section{PERFORMANCE MEASURES}

Considering the aforementioned strategies, we can compute the mean virtual time and the queue length. Several real-time problems can be designed using this model. This model can be designed in such a way to service its customers who enter into the system and into the waiting queue. The server can opt for vacation during which there are a-1 customers present in the system. The server can resume to service back if it finds least of "a" and highest of " $b$ " customers present in the system. If in a case that $b+1$ customers are present, then initial " $b$ " group of customers can be serviced leaving the rest in the queue. Finally at the vacation ending time, if there are a-1 customers, he can opt for recurrent vacation. The arriving customers choose to wait in queue and after sometime they may break. Some customers may choose not to get in and hence they eschew. These factors will be based on the service rate and the amount of customers present in the system. The intensity of traffic, virtual time, eschewing and breaking probability are shown in the table 1,2 and 3, figures 2,3 and 4respectively. The threshold value of traffic intensity threshold, $b_{i}=0.2$.

\begin{tabular}{|c|c|c|c|c|}
\hline $\begin{array}{c}\text { Vacation } \\
\text { Service } \\
\begin{array}{c}\text { Rate } \\
\mathrm{R}_{\mathrm{B}}\end{array}\end{array}$ & $\begin{array}{c}\text { Vacation } \\
\text { Rate } \mathrm{R}_{\mathrm{v}}\end{array}$ & $\begin{array}{c}\text { Mean } \\
\text { Virtual } \\
\text { Time }\end{array}$ & $\begin{array}{c}\text { Average } \\
\text { Balking } \\
\text { Rate }\end{array}$ & $\begin{array}{c}\text { Average } \\
\text { Reneging } \\
\text { Rate }\end{array}$ \\
\hline \multirow{5}{*}{0.1} & 3 & 1.8042 & 0.4936 & 2.7540 \\
\cline { 2 - 5 } & 2.5 & 1.4094 & 0.4890 & 2.6453 \\
\cline { 2 - 5 } & 2 & 1.324 & 0.4797 & 2.5104 \\
\cline { 2 - 5 } & 1.5 & 1.295 & 0.4590 & 2.3379 \\
\hline
\end{tabular}




\begin{tabular}{|l|c|c|c|c|}
\hline & 1 & 1.2776 & 0.4372 & 2.2236 \\
\cline { 2 - 5 } & 0.5 & 1.2693 & 0.4072 & 2.1079 \\
\hline
\end{tabular}

Table No 1: For the Vacation Rate 0.1

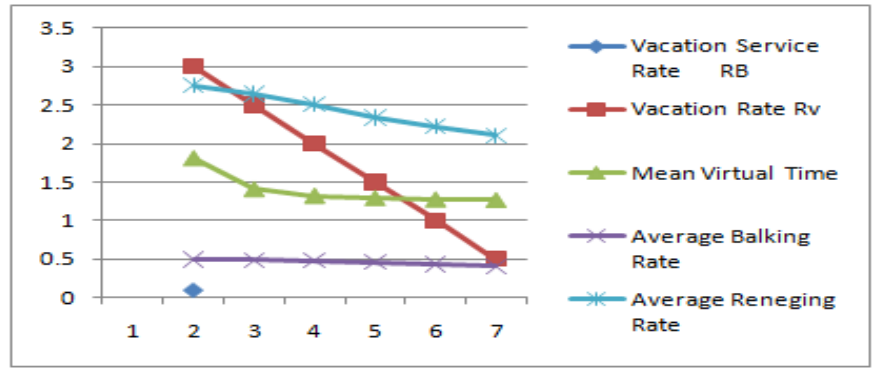

Figure No 2: For the Vacation Rate 0.1

\begin{tabular}{|c|c|c|c|c|}
\hline $\begin{array}{c}\text { Vacation } \\
\text { Service Rate } \\
\mathrm{R}_{\mathrm{B}}\end{array}$ & $\begin{array}{c}\text { Vacation Rate } \\
\mathrm{R}_{\mathrm{v}}\end{array}$ & $\begin{array}{c}\text { Mean } \\
\text { Virtual } \\
\text { Time }\end{array}$ & $\begin{array}{c}\text { Average } \\
\text { Balking Rate }\end{array}$ & $\begin{array}{c}\text { Average } \\
\text { Reneging Rate }\end{array}$ \\
\hline \multirow{5}{*}{0.3} & 3 & 1.5778 & 0.3823 & 1.8501 \\
\cline { 2 - 5 } & 2.5 & 1.3554 & 0.3765 & 1.7564 \\
\cline { 2 - 5 } & 2 & 1.3013 & 0.3682 & 1.6589 \\
\cline { 2 - 5 } & 1.5 & 1.2803 & 0.3528 & 1.5247 \\
\cline { 2 - 5 } & 1 & 1.2699 & 0.3421 & 1.3584 \\
\cline { 2 - 5 } & 0.5 & 1.2641 & 0.3156 & 1.2571 \\
\hline
\end{tabular}

Table No 2: For the Vacation Rate 0.3

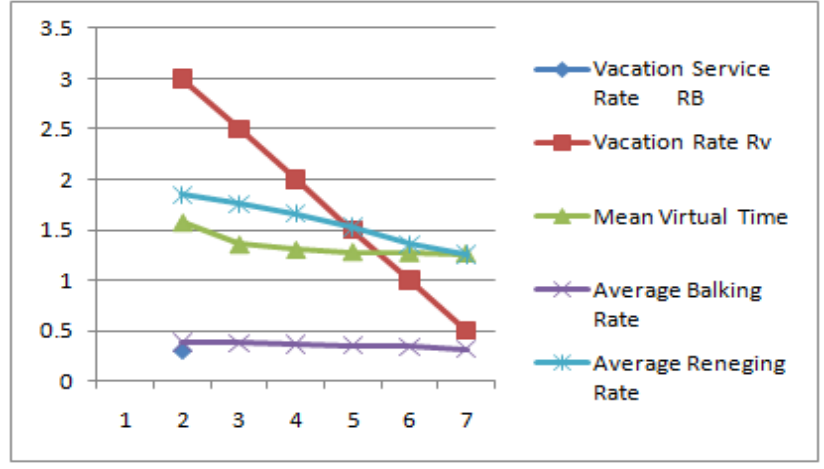

Figure No 3: For the Vacation Rate 0.3 


\begin{tabular}{|c|c|c|c|c|}
\hline $\begin{array}{c}\text { Vacation } \\
\text { Service } \\
\text { Rate } \\
\mathrm{R}_{\mathrm{B}}\end{array}$ & $\begin{array}{c}\text { Vacation } \\
\text { Rate } \mathrm{R}_{\mathrm{v}}\end{array}$ & $\begin{array}{c}\text { Mean } \\
\text { Virtual } \\
\text { Time }\end{array}$ & $\begin{array}{c}\text { Average } \\
\text { Balking } \\
\text { Rate }\end{array}$ & $\begin{array}{c}\text { Average } \\
\text { Reneging } \\
\text { Rate }\end{array}$ \\
\hline \multirow{6}{*}{0.5} & 3 & 1.4357 & 0.2965 & 0.3952 \\
\cline { 2 - 5 } & 2.5 & 1.3152 & 0.2854 & 0.3753 \\
\cline { 2 - 5 } & 2 & 1.283 & 0.2632 & 0.3621 \\
\cline { 2 - 5 } & 1.5 & 1.2699 & 0.2563 & 0.3587 \\
\cline { 2 - 5 } & 0.5 & 1.2633 & 0.2491 & 0.3475 \\
\hline
\end{tabular}

Table No 3: For the Vacation Rate 0.5

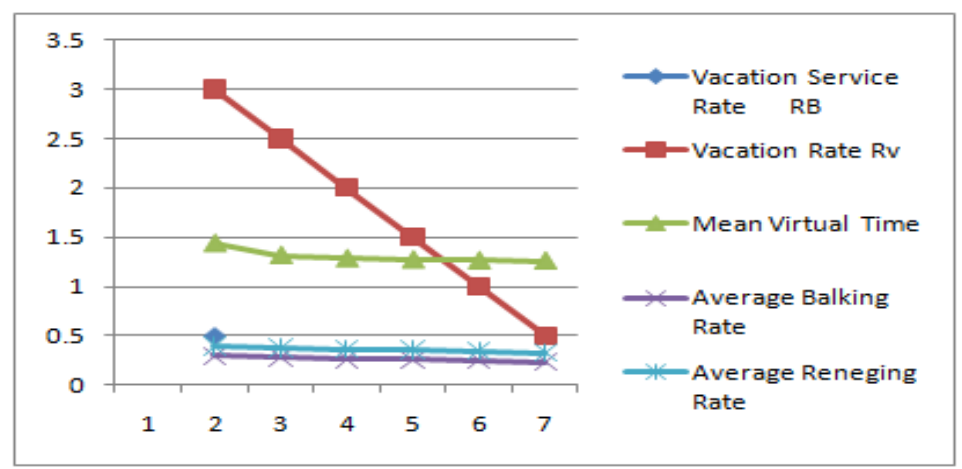

Figure No 4: For the Vacation Rate 0.5

\begin{tabular}{|c|c|c|c|c|}
\hline $\begin{array}{c}\text { Vacation Service } \\
\text { Rate } \mathrm{R}_{\mathrm{B}}\end{array}$ & $\begin{array}{c}\text { Vacation } \\
\text { Rate } \mathrm{R}_{\mathrm{v}}\end{array}$ & $\begin{array}{c}\text { Mean Virtual } \\
\text { Time }\end{array}$ & $\begin{array}{c}\text { Average } \\
\text { Balking Rate }\end{array}$ & $\begin{array}{c}\text { Average } \\
\text { Reneging Rate }\end{array}$ \\
\hline \multirow{5}{*}{0.1} & 3 & 1.8042 & 0.4936 & 2.7540 \\
\cline { 2 - 5 } & 2.5 & 1.4094 & 0.4890 & 2.6453 \\
\cline { 2 - 5 } & 2 & 1.324 & 0.4797 & 2.5104 \\
\cline { 2 - 5 } & 1.5 & 1.295 & 0.4590 & 2.3379 \\
\cline { 2 - 5 } & 1 & 1.2776 & 0.4372 & 2.2236 \\
\hline \multirow{5}{*}{0.3} & 3 & 1.2693 & 0.4072 & 2.1079 \\
\cline { 2 - 5 } & 2.5 & 1.5778 & 0.3823 & 1.8501 \\
\cline { 2 - 5 } & 2 & 1.3554 & 0.3765 & 1.7564 \\
\cline { 2 - 5 } & 1.5 & 1.3013 & 0.3682 & 1.6589 \\
\cline { 2 - 5 } & 1 & 1.2699 & 0.3528 & 1.5247 \\
\cline { 2 - 5 } & 0.5 & 1.2641 & 0.3421 & 1.3584 \\
\cline { 2 - 5 } & 3 & 1.4357 & 0.2965 & 0.3952 \\
\cline { 2 - 5 } & 2.5 & 1.3152 & 0.2854 & 0.3753 \\
\cline { 2 - 5 } & 2 & 1.283 & 0.2632 & 0.3621 \\
\hline \multirow{5}{*}{0.5} & 1.5 & 1.2699 & 0.2563 & 0.3587 \\
\hline
\end{tabular}




\begin{tabular}{|c|c|c|c|c|}
\hline & 1 & 1.2633 & 0.2491 & 0.3475 \\
\cline { 2 - 5 } & 0.5 & 1.2595 & 0.2354 & 0.3286 \\
\hline
\end{tabular}

Table No 4: Final comparison table of the vacation rate.

While the waiting line traverse quicker, the server will continue to offer its service until the queue has a-1 number of customers prevail in the system. The rate of vacation of a customer possess considerable impact over the waiting line's length and the rate of vacation can be set while it falls below the "a" amount of customers in the system. This model continues to offer its service till the level of the customer reaches a-1. Hence the probability of eschewing and breaking suppressed since the vacation level of the server suppresses.

\section{CONCLUSION}

The queuing model $\mathrm{M}\left|\mathrm{M}^{(\mathrm{a}, \mathrm{b})}\right| 1$ is designed for single server with multiple vacations. In this model, the vacation rate of a customer is decreased based on the amount of customers in the system. The model is designed based on high service rate and low vacation rate to reduce the eschewing and breaking probability. The two cases are taken to improve the eschewing and breaking strategy. In the unobservable waiting line - the system state is not observed by the customer when he decides to join the queue and after some time impatient customers may break or eschew. In the partially waiting line - the current position of the server is noticed by the customer but failed to notice the queue size and then decides to enter the queue and impatient customers may break or eschew.

\section{REFERENCES}

[1] Afthab Begum. M. I, "Queueing models with bulk service and vacation”, (1996), Ph.D, Dissertation, Bharathiar university, Coimbatore, Tamilnadu, India.

[2] Doshi.B.T(1986),'Queueing systems with vacations. A survey”, Queueing systems, Vol.1, 2966.

[3] Kao, C., Li, C., and Chen,S., (1993), "Parametric programming to the analysis of fuzzy queues", Fuzzy sets and system, vol.107, pp.93-100

[4] Madan.K.C and AI-Rawwash.M(2005),'On the Mx/G/1 queue with feedback and optional server vacations based on a single vacation policy", Applied mathematical and computations, Vol 160, 909 -919. 
[5] Medhi. J. H and Borthakur. A, " On a two server Markovian queue with a general bulk service rule", Cahiers duecentre d' Etudes de Rechercheoperationnelle, (1972), Vol.21, 183 - 189.

[6] Nagoor Gani .A and Ashok Kumar .v (2009), "A bulk arrival queueing model with fuzzy parameters and fuzzy varying batch size", BPAS Research, vol.2,no.333.

[7] Naishuo Tian and Xinqiu Zhao (2008), "The M/M/1 Queue with Single Working Vacation", International Journal of Information and Management Sciences, Volume 19, Number 4, pp. 621634.

[8] Palpandi .B, Geethamani .G (2013), "Evaluation of Performance of bulk arrival queue with fuzzy parameters using Robust Ranking Technique", International journal of computing Engineering research, vol.03, issue 10, pp.53-57.

[9] Servi, LD., and Finn, S.G., (2002) "M/M/1 queues with working vacations(M/M/1/WV)", Performance Evauation,Vol.50,pp. 41-52, 2002.

[10] Tian, N., Li, J., and Zhang, G., "Matrix analytic method and working vacation queue-A survey", International Journal of Information Management Sciences,Vol.20,pp.603-633, 2009.

[11] Wu, D. and Takagi, H. (2006), “An M / G / 1 queue with multiple working vacations", Performance Evaluation, 63, 654-681.

[12] Zadeh, (1965), “Fuzzy Sets”, Information and Control, Vol 5(3), pp:338. 